\title{
HAUNTING RHETORIC, HAUNTED EPISTEMOLOGY: AN ANTHROPOLOGICAL CRITIQUE OF SYSTEMICS IN ARCHITECTURE AND URBAN STUDIES
}

\author{
Author(s) / Auteur(s) : \\ Corentin CHANET \\ PhD Student \\ Anthropology Laboratory of Contemporary Worlds (LAMC), Brussels \\ cchanet@ulb.ac.be \\ David EUBELEN \\ Researcher \\ Architecture and Social Sciences (SASHA), Brussels \\ deubelen@ulb.ac.be
}

Keywords / Mots-clés :

systemics, architecture, urban, critical anthropology, epistemology

\begin{abstract}
Although the need for a more complex, interdisciplinary approach to architecture, urban and social systems is well recognized, there are still huge efforts to be made in order to go beyond a mere juxtaposition of different research fields. Systemic studies can rightfully appear at the forefront of this interdisciplinary trend, but we believe that if we want to effectively bolster it, we need to be much more critical of the conceptual framework that will act as the bridge between the different fields.

Our main contention for this paper is that systemic approaches developed in/for architecture and urban studies generate a haunting rhetoric based upon a haunted epistemology. After having explained what we mean by these, we will conclude with a series of fundamental discontinuities that should be at the centre of architectural and urban research. But before we get there, we would like to mention that our goal is not to be provocative (even though we certainly are to some extent) and we would feel rather embarrassed if our proposal was to be seen either as an attack or a condescending rejection of systemic approaches in general. So let us clear the air by saying that in our mind, systemic approaches have played for years an vital role in fostering interdisciplinary research at the crossroads of cognitive sciences, social sciences, architecture and urban studies (among plenty of other fields), and that is why we feel the need to show some tough love by questioning the merits of seeing feedback loops and emergent organization at every street corner - notwithstanding the fact that some "streets" (i.e. places) and some "corners" (i.e. scales) are more taken into consideration than others in urban and architecture studies.
\end{abstract}

\section{HAUNTED EPISTEMOLOGY}

There are several issues to address, among which is the constructivist perspective that allows systems and systemic features to be applied to any abstracted entity, which in turn paradoxically generates a false sense of objectivity and universality: a model of reality is all the more easily taken as reality itself when it is not bounded by any scale nor confined within any particular realm. Inscribing systemics in an "observer-dependent" constructivism does not prevent the subsequent epistemology to be afflicted by biases and essentialism, what we call a haunted epistemology. Again, we do not dispute that systemic models have some instrumental efficacy across a wide range of scales or contexts; however we would argue that systemic models are very poor descriptors outside the realm of mathematics and physics, and that their epistemological status is at the very least questionable. Universality of concepts like "homeostasis", "emergence", "equilibrium", "autonomy”, etc. may very 
well be the corollary of their emptiness. Lexical similarities and formal conflations tend to be mystifying and cannot therefore provide a pathway to interdisciplinary research. So if certain emergent properties of a human crowd can effectively be abstracted by a systemic model that originated from physics, here's the problem: social interactions cannot be described as sophisticated collisions because people are not particles. The fact that a formal conflation is effective does not prove its validity as a scientific concept. But what if proponents of systemics argue that the only goal set for their approach is precisely to be effective, to offer a hold on the world, and nothing more? Well, that leads us to our second set of critical remarks.

\section{HAUNTING RHETORIC}

As we've just said, there's no denying that systemic models can be very powerful in terms of projection, decision-making and justification. However, we don't think that systemic models are convincing solely because they are efficient. There is also the rhetoric, i.e. the convincing nature of the systemic discourse, propped up by a formal aesthetics that displays a sense of universality, openness and complexity, all values that can appeal to contemporary designers and policy-makers alike. That is precisely the reason why systemics is a haunting rhetoric: it promises a universal way to govern any kind of phenomena by formalizing some properties, from superconductivity to urban design. And while its appearance remains non-political, thanks to the common representation of its origin (hard sciences like thermodynamics) and its formalization (mathematics), this rhetoric keeps being used as an ideology (Boltanski \& Bourdieu, 1976) to support policies, to define quality, to rebrand discourses of good governance, to foster dominant interests, etc. Exorcised architecture: from complexity to messiness

So where do these considerations lead us in terms of urban and architectural practices and research? First it allows us to reconsider critically the idea of a systemic continuity between architectural/urban design, the built environment and social entities like norms, behaviours, institutions, etc. What strikes us the most as social scientists are the discontinuities between these contiguous entities: policies and urban planning are imposed even when some participatory initiatives are put in place; urban spaces are at the same time homogenized and fragmented to maximize the circulation of capital and strategies of accumulation (Harvey, 2013; Lefebvre, 1974); "extended' cognitive and systemic models of innovation in architecture and urban design often fail to seriously take into account the embodiment of habits (Turner, 1994; Turner, 2014; Bourdieu, 1972) which are not only mental representations (Dreyfus, 2002), therefore reinforcing an external/internal cleavage that is damaging for the understanding of living organisms. To posit a formal systemic continuity between material configurations and social processes (or vice-versa) is of little help to tackle these challenges. We want to advocate a shift from an aesthetical complexity appealing for policy-makers to the contingent and diverse empirical messiness that is neither systemic nor non-systemic. What we lose in efficient formalizations and decision-making, we regain in thick descriptions and deeper understanding achieved through empathy and participant observation that put matters of life, death and politics at the centre of architecture and urban design. We can dwell on models and mediums of representation for hours within the comfort of our labs, but that will not help us to understand or decide what is or has to be represented, who has the power to do so and why. As Godlewski (2010) wrote in his critique of the work done by Koolhaas for the Harvard Project on the City (see also Crysler, 2012), we shouldn't think about complexity and rapidly changing environments from the height of a helicopter circling over a city if we want to avoid the pitfalls of cybernetic orientalism.

\section{REFERENCES}

BOLTANSKI, Luc \& BOURDIEU, Pierre (1976). "La Production de L'idéologie Dominante." Actes de La Recherche En Sciences Sociales 2 (2). Maison des sciences de l'homme: 3-73. doi:10.3406/arss.1976.3443.

BOURDIEU, Pierre (1972). Esquisse D’une Théorie de La Pratique. Poche. Seuil. 
CRYSLER, Christophe Greig (2012). "Introduction: Time's Arrows: Spaces of the Past." In The SAGE Handbook of Architectural Theory, edited by Christophe Greig Crysler, Stephen Cairns, and Hilde Heynen, 289-307. SAGE.

DREYFUS, Hubert L. (2002). "Intelligence Without Representation-Merleau-Ponty's Critique of Mental Representation the Relevance of Phenomenology to Scientific Explanation." Phenomenology and the Cognitive Sciences 1 (4): 367-83.

GODLEWSKI, Joseph. (2010). "Alien and Distant: Rem Koolhaas on Film in Lagos, Nigeria.” Traditional Dwellings and Settlements Review 23 (2): 7-19.

HARVEY, David. (2013). Rebel Cities: From the Right to the City to the Urban Revolution. Verso Books.

LEFEBVRE, Henri (1974). La Production de L'espace. Anthropos.

TURNER, Stephen P. (1994). The Social Theory of Practices: Tradition, Tacit Knowledge and Presuppositions. Cambridge [England]: Polity Press.

TURNER, Stephen P. (2014). Understanding the Tacit. New York: Routledge. http://site.ebrary.com/id/10829748. 
